\title{
Pengaruh Kapasitas Kapasitor Pada Kumparan Bantu Terhadap Pemanasan Motor Induksi Satu Fasa
}

\author{
Emidiana \\ Dosen Tetap Yayasan pada Program Studi Teknik Elektro \\ Fakultas Teknik Universitas PGRI Palembang \\ e-mail : emidianaal@yahoo.com
}

\begin{abstract}
ABSTRAK
Motor yang paling banyak digunakan dalam kehidupan sehari-hari adalah motor induksi 1 fasa, karena harganya yang relatif murah dan mudah untuk dioperasikan. Dalam pemakaian sehari-hari, motor induksi 1 fasa sering mengalami kerusakan karena pemanasan. Sebagian besar pemanasan yang terjadi disebabkan oleh rusaknya kapasitor start, yang menyebabkan menurunnya kecepatan motor dan dapat menyebabkan arus hubung singkat. Bila hubung singkatnya terjadi dalam waktu yang lama, energy panas yang terjadi akan semakin besar dan dapat menyebabkan kerusakan isolasi kumparan. Hal ini dapat diatasi dengan mengganti kapasitor yang rusak tersebur. Dari hasil perhitungan didapat bahwa Semakin besar nilai kapasitor, maka semakin kecil nilai rugi-rugi daya dan rugi - rugi energi motor induksi tersebut.
\end{abstract}

Kata kunci : Motor Induksi, 1 Fasa, Kapasitor

\section{ABSTRACT}

The most used to motor in daily life is a single phase induction motor, because they have low cost and easy to operate. In daily life, 1 phase induction motor is usually get broken because of the heat. Most of the heat happened because of the broken start capacitor and it cause to decrease the motor speed and cause short circuit current. When this happened for a long time motor become heater and can cause the broken of winding insulation. We can handle this by changing the broken capacitor. From the result of calculation, we know that the higher the value of capacitor, the lower power losses and energy losses of the motor induction

Keyword : Induction Motor, 1 phase, Capacitor

\section{PENDAHULUAN}

Motor induksi adalah motor yang mudah dioperasikan dan harganya relatif murah. Dalam kehidupan sehari-hari, banyak digunakan untuk penggerak alat yang membutuhkan daya yang rendah dan kecepatan yang relatif konstan. Hal ini dikarenakan motor induksi satu fasa mempunyai berbagai kelebihan antara lain konstruksinya yang sederhana dan kecepatan yang hampir konstan. Motor induksi 1 fasa banyak digunakan pada alat rumah tangga, antara lain sebagai penggerak kipas angin, pompa air, dll. Pada saat pemakaiannya, motor induksi sering mengalami gangguan baik berupa gangguan secara mekanik, maupun elektris.

Pada penelitian ini akan dilakukan pembahasan mengenai rugi-rugi untuk bermacam kapasitas dari kapasitor yang terjadi pada motor induksi 1 fasa 


\section{TINJAUAN PUSTAKA}

Motor induksi adalah peralatan konversi energy listrik yang merubah energy listrik menjadi energy mekanik, dengan berdasarkan prinsip induksi electromagnet. Motor induksi merupakan motor asinkron, karena motor ini beroperasi pada kecepatan dibawah kecepatan sinkron. Kecepatan sinkron adalah kecepatan rotasi medan magnetik pada mesin Muhammad robith

\section{Prinsip Kerja Motor Induksi 1 Fasa}

Motor induksi bekerja berdasarkan prinsip induksi elektromagnet. Kumparan stator diberi tegangan, sehingga inti besinya menjadi magnet, yang kemudian akan menginduksikan ke rotor. Kumparan rotor merupakan loop tertutup, sehingga arus mengalir pada kumparan rotor tersebut. Arus rotor tersebut akan berinteraksi dengan medan magnet stator, yang menghasilkan gaya putar pada rotor. Kumparan stator akan menghasilkan medan putar dengan kecepatan sinkron. Misal motor dalam kondisi berhenti, stator dihubungkan dengan jaringan, sedangkan kumparan rotor merupakan rangkaian tertutup, maka kondisi seperti ini seperti sebuah transformator, dengan kumparan stator adalah kumparan primernya dan kumparan pada rotor adalah kumparan sekundernya ( Abdul Kadir, $1981: 8$ ) rotor Motor induksi satu fasa punya satu kumparan stator, dengan input satu fasa, dan untuk menstart motornya harus ada alat bantu. Berbeda dengan motor induksi 3 fasa, pada motor induksi satu fasa tidak terjadi medan magnet putar. Sehingga masih perlu dipasang kumparan bantu untuk mengawali berputar. Seperti pada gambar berikut, dimana kumparan utama $U_{1}-U_{2}$ dan kumparan bantu $\mathrm{Z}_{1}-\mathrm{Z}_{2}$ terlihat pada gambar berikut

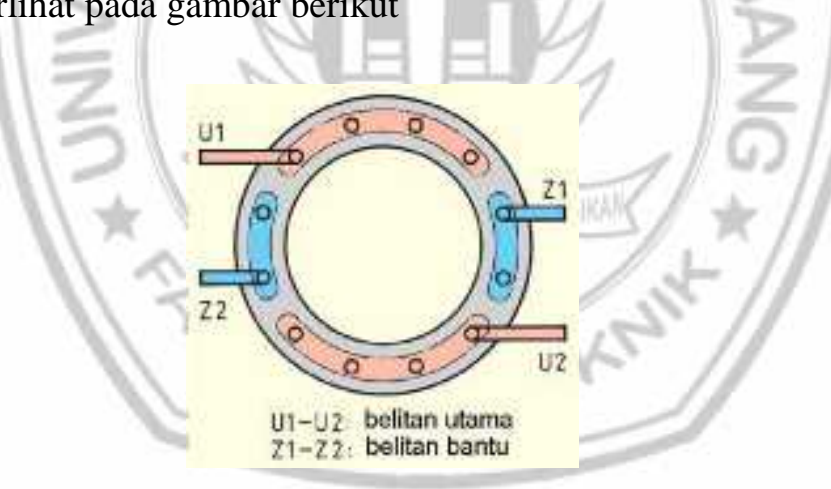

Gambar 1. Medan Magnet Utama dan Medan magnet Bantu pada Motor Satu Phasa http://siapbelajar.com/wp-content/uploads/2013/09/6 102Teknik-Listrik-Indus-Jilid-2.pdf

Pada motor induksi 1 fasa, beda fasa tegangannya $180^{\circ}$ yang menyebabkan getaran pada rotor, karena medan putar kekanannya sama dengan medan putar kekiri. Agar terjadi medan putar pada motor induksi 1 fasa, pada stator harus ada 2 kumparan yaitu kumparan utama dan kumparan bantu. Kumparan utama dan kumparan bantu diparalelkan, kemudian dipasang kapasitor secara seri dengan kumparan bantu. Karena adanya kapasitor yang terhunung seri dengan kumparan bantu, maka antara kumparan utama dan kumparan bantu akan terjadi beda fasa $90^{\circ}$. Saat putaran rotor mencapai $75 \%$ dari nominalnya, sakelar akan memutus sumber tegangan kekumparan bantu

Putaran fluksi medan stator dinyatakan dengan rumus :

$$
\mathrm{Ns}=\frac{1 \quad f}{r}
$$

Dimana

$$
\begin{aligned}
& \text { Ns }=\text { Putaran fluks medan stator } / \text { kecepatan sinkron (rpm) } \\
& F=\text { Frekuensi }(\mathrm{Hz}) \\
& P=\text { Jumlah kutub }
\end{aligned}
$$


Pada motor induksi, tegangan induksi pada rotor akan ada, jika medan putar stator memotong batang konduktor di rotor, atau dengan kata lain agar tegangan pada rotor terinduksi, harus ada perbedaan putaran relative antara medan putar stator $(\mathrm{Ns})$ dengan putaran rotor $(\mathrm{Nr})$, yang dinamakan slip (s)

$$
\begin{aligned}
& \mathrm{S}=\frac{N_{\mathrm{a}}-N_{T}}{N_{\mathrm{a}}} \\
& \% \mathrm{~S}=\frac{N_{\mathrm{a}}-N_{T}}{N_{\mathrm{a}}} \times 100 \%
\end{aligned}
$$

Dimana : $\quad S=$ Slip

$$
\text { Ns = kecepatan putaran medan stator (rpm) }
$$

$\mathrm{Nr}=$ putaran rotor

\section{Konstruksi Motor Induksi}

Secara umum, motor induksi terdiri atas 2 bagian utama, yaitu : stator dan rotor. Bagian yang diam (stator) dan bagian yang bergerak (rotor). Terdapat celah udara diantara keduanya. Konstruksi motor induksi dapat dilihat pada gambar berikut :

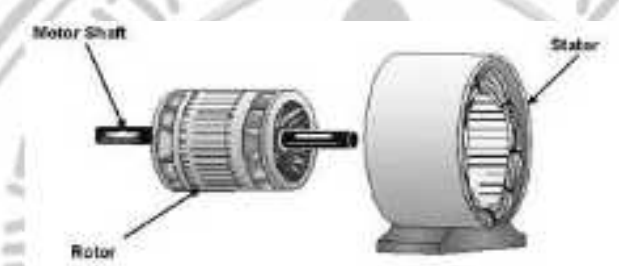

Gambar 2. Konstruksi Motor Induksi

http://repository.usu.ac.id/bitstream/handle/123456789/30098/Chapter\%20ll.pdf;jsessionid=BE563E $\underline{5 A 82758 C 801 F 39 F 545508 A 4 B 49 \text { ? sequence }=4}$

\section{Stator}

Stator merupakan bagian yang paling luar dari motor, merupakan bagian yang diam dan mengalirkan arus phasa. Stator terdiri dari lapisan pelat baja beralur, tempat kumparan dililitkan yang didukung dalam rangka yang terbuat dari besi tuang atau pelat baja. Motor induksi satu fasa mempunyai dua kumparan stator yang dipasang terpisah, yaitu kumparan utama (main winding) dan kumparan bantu (auxiliary winding).

Komponen stator motor induksi tiga fasa, seperti pada gambar berikut :

(a). lempengan inti

(b). tumpukan inti dengan kertas isolasi pada beberapa alurnya

(c). tumpukan inti dan belitan dalam caking statornya

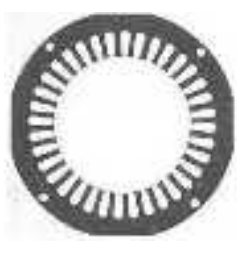

(a)

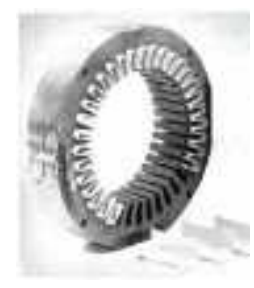

(b)

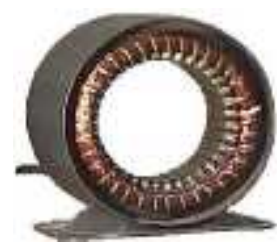

(c)

Gambar 3. Komponen Stator

http://repository.usu.ac.id/bitstream/handle/123456789/30098/Chapter\%20ll.pdf;jsessionid=BE563 E5A82758C801F39F545508A4B49?sequence $=4$ 
Sumber tegangan AC terhubung ke stator. Secara listrik, rotor tidak terhubung langsung ke sumber tegangan bolak-balik, tetapi mempunyai arus induksi.

\section{Rotor}

Rotor adalah bagian motor induksi yang berputar, yang terdiri dari : inti rotor, kumparan rotor dan alur rotor. Rotor pada motor induksi terdiri atas 2 tipe, yaitu tipe rotor belitan (wound rotor) dan tipe rotor sangkar (squirrel cage rotor).

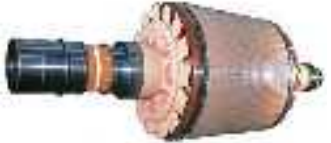

(a).tipikal rotor sangkar

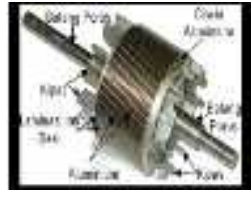

(b).bagian-bagian rotor sangkar

Gambar 4 Konstruksi rotor motor induksi rotor sangkar

http://repository.usu.ac.id/bitstream/handle/123456789/30098/Chapter\%20ll.pdf;isessionid=BE563 E5A82758C801F39F545508A4B49? sequence $=4$

Motor sangkar tupai adalah rotor dengan konstruksi inti berlapis, konduktornya dipasang secara parallel dengan poros dan mengelilingi permungkaan inti. Arus rotor akan mengalir melalui konduktor rotor. Konduktor rotor dihubungsingkat dengan cincin ujung. Konstruksi rotor belitan berbeda dengan konstruksi sangkar tupai. Rotor dililit dengan lilitan terisolasi seperti pada stator, masing-masing fasa ujungnya terbuka lalu ke cincin slip yang yang ada pada poros motor.

\section{Motor Kapasitor}

Motor induksi 1 fasa terbagi atas beberapa macam, yaitu :

1. Motor Kapasitor

2. Motor Shaded Pole

3. Motor Universal.

Motor pada peralatan rumah tangga seperti yang digunakan untuk pompa air, mesin cuci, kulkas dll umumnya merupakan motor kapasitor. Arus yang melewati kumparan utama tertinggal dari tegangan, dengan menggunakan kapasitor dengan ukuran yang tepat, arus pada kumparan start dibuat mendahului tegangan. (Lister, 1988 : 24 ). Sudut fasa kumparan utama dan kumparan bantu dibuat mendekati $90^{\circ}$. Untuk motor kapasitor diatas $1 \mathrm{~kW}$, mempunyai 2 kapasitor, yaitu kapasitor kerja dan kapasitor bantu serta satu sakelar. 2 buah kapasitor tersebut fungsinya adalah meningkatkan torsi awal. Setelah rotor berputar mendekati $70 \%$ putaran nominalnya, sakelar membuka sehingga hanya 1 kapasitor yang digunakan (kapasitor kerja).

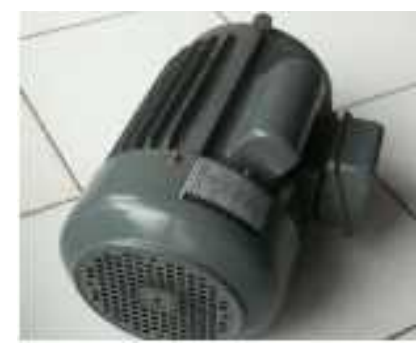

Gambar 2.6.Bentuk Fisik Motor Kapasitor http://sasing.unimus.ac.id/files/disk1/155/itptunimus-gdl-herisuryoc-7703-3-babii.pdf 


\section{Pemanasan Pada Motor Induksi 1 Fasa}

Pemanasan pada motor induksi 1 fasa dapat disebabkan oleh rugi-rugi. Rugi-rugi pada motor induksi, dapat disebabkan oleh komponen pada motor itu sendiri, yaitu :

- Pada inti, terdapat rugi-rugi hysteresis dan arus eddy yang dipengaruhi oleh konstruksi motor itu sendiri

- Pada kumparan utama dan kumparan bantu, terdapat rugi-rugi tembaga $I^{2} R$. Penampang kawat tembaga pada kumparan utama lebih besar jika dibandingkan dengan kumparan bantu, sehingga impedansinya lebih kecil, dengan demikian rugi-ruginya juga lebih kecil dibanding kumparan bantu.

- Rugi-rugi mekanik karena gesekan dan angin

Sebagian besar pemanasan yang terjadi pada motor induksi 1 fasa disebabkan oleh rusaknya kapasitor start, yang menyebabkan menurunnya kecepatan motor dan dapat menyebabkan arus hubung singkat. Bila hubung singkatnya terjadi dalam waktu yang lama, energy panas yang terjadi akan semakin besar dan dapat menyebabkan kerusakan isolasi kumparan.

\section{METODE PENELITIAN}

Penelitian ini menggunakan motor induksi 1 fasa penggerak pompa air, dengan data-data sbb :

- Jenis Motor : Induksi rotor sangkar

- Fasa $\quad: 1$

- Tegangan $: 220 \mathrm{~V}$

- Frekwensi : :50 Hz

- Kecepatan $\quad: 1450 \mathrm{rpm}$

- Daya : : $0,75 \mathrm{HP}$

- Kutub $\quad: 4$

Pengujian dilakukan di Laboratorium Mesin-mesin Elektrik Universitas PGRI Palembang

Tahapan penelitian adalah Sbb :

1. Mengoperasikan motor induksi 1 fasa tanpa beban selama 15 menit dengan alat bantu start berupa kapasitor yang mempunyai kapasitas masing - masing : $25 \mu \mathrm{F}, 16 \mu \mathrm{F}, 8 \mu \mathrm{F}$ non polar. Dimana antara satu pengujian dengan pengujian yang lain, diberikan renggang waktu yang cukup lama menunggu kumparan menjadi dingin, yang dibantu dengan alat pendingin berupa kipas yang dihembuskan langsung ke kumparan.

2. Mengukur arus start, waktu start, tegangan kerja, arus nominal, temperatur kumparan , kecepatan

3. Melakukan perhitungan untuk mendapatkan nilai rugi-rugi daya dengan berbagai ukuran kapasitor, dengan tahapan :

- Menentukan resistansi kumparan utama dan kumparan bantu dengan sumber tegangan searah yang berubah-ubah, menggunakan rumus :

$$
\begin{aligned}
& K_{d}=\frac{V_{a}}{l_{a}} \\
& K_{a}=\text { k. } K_{d}
\end{aligned}
$$

Dimana : $K_{d}=$ tahanan searah

$K_{a}=$ tahanan bolak-balik

$\mathrm{k}=$ konstanta akibat efek kulit $=1,5$ untuk daerah tropis 
4. Melakukan perhitungan untuk mendapatkan nilai rugi-rugi daya dengan berbagai ukuran kapasitor, dengan tahapan :

- Menentukan resistansi kumparan utama dan kumparan bantu dengan sumber tegangan searah yang berubah-ubah, menggunakan rumus :

$$
\begin{aligned}
& K_{d}=\frac{V_{a}}{l_{a}} \\
& K_{a}=\mathrm{k} . K_{d}
\end{aligned}
$$

Dimana :

$$
\begin{aligned}
& K_{d}=\text { tahanan searah } \\
& K_{a}=\text { tahanan bolak-balik } \\
& \mathrm{k}=\text { konstanta akibat efek kulit }=1,5 \text { untuk daerah tropis }
\end{aligned}
$$

- Menentukan rugi-rugi daya dan energy pada kumparan utama dan kumparan bantu, dengan menggunakan rumus :

$$
\begin{aligned}
& \Delta Y=l^{2} \cdot K_{k 1} \\
& \Delta W=\Delta P \cdot t \\
& \text { Dimana : } \quad \Delta Y=\text { Rugi-rugi daya }
\end{aligned}
$$$$
\Delta W=\text { Rugi-rugi energi }
$$$$
k_{k 1} \quad \text { = tahanan kumparan }
$$$$
t=\text { waktu }
$$

Dari hasil pengujian didapat data- data sbb :

Tabel 1. Hasil Pengujian Motor Induksi 1 Fasa

\begin{tabular}{|c|c|c|c|c|c|c|c|c|}
\hline No. & $\begin{array}{c}\text { Capasitor } \\
(\mu)\end{array}$ & $\begin{array}{c}\mathrm{I}_{\text {start }} \\
(\mathrm{Amp})\end{array}$ & $\begin{array}{c}\mathrm{V}_{\text {nominal }} \\
(\text { Volt })\end{array}$ & $\begin{array}{c}\mathrm{I}_{\text {nominal }} \\
(\text { Ampere })\end{array}$ & $\begin{array}{c}\text { Temp } \\
\text { Kumparan } \\
\left({ }^{0} \mathrm{C}\right)\end{array}$ & $\begin{array}{c}\text { Kecepatan } \\
\text { Rotor } \\
(\mathrm{rpm})\end{array}$ & $\begin{array}{c}\text { Waktu } \\
\text { Start } \\
(\mathrm{detik})\end{array}$ & $\begin{array}{c}\mathrm{I}_{\mathrm{kb}} \\
(\text { Ampere })\end{array}$ \\
\hline 1 & 25 & 5,7 & 220 & 1,21 & 14 & 1478 & 0,57 & 0,3 \\
\hline 2 & 16 & 6,6 & 220 & 1,55 & 17 & 1464 & 0,59 & 0,5 \\
\hline 3 & 8 & 7,8 & 220 & 1,73 & 29 & 1438 & 0,79 & 0,6 \\
\hline
\end{tabular}

Pengujian juga dilakukan untuk mendapatkan nilai resistansi kumparan utama dan kumparan bantu dengan cara memberikan sumber dc, dengan hasil sbb :

Tabel 2. Hasil Menggunakan sumber tegangan DC

\begin{tabular}{|l|c|c|c|}
\hline No. & $\mathrm{V}_{\mathrm{dc}}($ Volt $)$ & $\mathrm{I}_{\mathrm{dc}}$ pada kump utama (Ampere) & $\mathrm{I}_{\mathrm{dc}}$ pada kump bantu (Ampere) \\
\hline 1 & 20 & 6,4 & 12,5 \\
\hline 2 & 14 & 4,4 & 8,7 \\
\hline 3 & 8 & 2,4 & 5,0 \\
\hline
\end{tabular}

\section{HASIL PERHITUNGAN}

Tabel 4. Hasil Perhitungan nilai resistansi kumparan

\begin{tabular}{|c|c|c|}
\hline No. & $\mathrm{R}_{\mathrm{ku}}(\Omega)$ & $\mathrm{R}_{\mathrm{kb}}(\Omega)$ \\
\hline 1 & 4,6875 & 2,4 \\
\hline 2 & 4,77 & 2,41 \\
\hline 3 & 5,0 & 2,4 \\
\hline Rata-rata & 4,82 & 2,4 \\
\hline
\end{tabular}


Tabel 5.Hasil Perhitungan Rugi-rugi Daya

\begin{tabular}{||l|l|l|l||}
\hline \hline \multirow{2}{*}{\multicolumn{1}{|c|}{ Rugi-rugi }} & \multicolumn{3}{c|}{ Kapasitor } \\
\cline { 2 - 4 } & \multicolumn{1}{|c|}{$25 \mu \mathrm{F}$} & \multicolumn{1}{c|}{$16 \mu \mathrm{F}$} & \multicolumn{1}{|c|}{$8 \mu \mathrm{F}$} \\
\hline \hline Rugi2 Daya Kumparan Utama Saat Start & $156,602 \mathrm{~W}$ & $209,96 \mathrm{~W}$ & $292,032 \mathrm{~W}$ \\
\hline Rugi2 Energi Kumparan Utama Saat Start & $89,263 \mathrm{~J}$ & $104,98 \mathrm{~J}$ & $230,705 \mathrm{~J}$ \\
\hline Rugi2 Daya Kumparan Utama Saat Operasi Normal & $3,99 \mathrm{~W}$ & $4,44 \mathrm{~W}$ & $6,129 \mathrm{~W}$ \\
\hline Rugi2 Energi Kumparan Utama Saat Operasi Normal & $3588,726 \mathrm{~J}$ & $3993,38 \mathrm{~J}$ & $5511,258 \mathrm{~J}$ \\
\hline Rugi2 Daya Kumparan Bantu Saat Operasi Normal & $0,216 \mathrm{~W}$ & $0,6 \mathrm{~W}$ & $0,864 \mathrm{~W}$ \\
\hline Rugi2 Energi Kumparan Bantu Saat Operasi Normal & $194,4 \mathrm{~J}$ & $540 \mathrm{~J}$ & $777,6 \mathrm{~J}$ \\
\hline \hline Total Rugi2 Daya & $\mathbf{1 6 0 , 8 0 6} \mathbf{~ W}$ & $\mathbf{2 1 5} \mathbf{~ W}$ & $\mathbf{2 9 9 , 0 2 5} \mathbf{~ W}$ \\
\hline Total Rugi2 Energi & $\mathbf{3 8 7 2 , 3 9}$ J & $\mathbf{4 6 3 8 , 3 6 ~ J}$ & $\mathbf{6 5 1 9 , 5 6 ~ J}$ \\
\hline \hline
\end{tabular}

\section{KESIMPULAN}

1. Nilai total rugi-rugi daya untuk kapasitor $25 \mu \mathrm{F}=160,806 \mathrm{~W}$, kapasitor $16 \mu \mathrm{F}=215 \mathrm{~W}$ dan $8 \mu \mathrm{F}$ $=299,025 \mathrm{~W}$

2. Nilai total rugi-rugi energi untuk kapasitor $25 \mu \mathrm{F}=3872,39 \mathrm{~J}$, kapasitor $16 \mu \mathrm{F}=4638,36 \mathrm{~J}$ dan 8 $\mu \mathrm{F}=6519,56 \mathrm{~J}$

3. Nilai kapasitor dan nilai rugi-rugi berbanding terbalik. Semakin kecil nilai kapasitor, semakin besar nilai rugi-rugi daya dan rugi - rugi energi motor induksi tersebut.

\section{DAFTAR PUSTAKA}

1. Eugene C. Lister, Mesin dan Rangkaian Listrik, Penerbit Erlangga, Jakarta, 1988

2. Abdul Kadir, Ir, "Mesin Tak Serempak" Penerbit Djambatan, Jakarta, 1981

3. Baharudin, Skripsi, Analisis Pengaruh Pembebanan Terhadap Karakteristik (Unjuk Kerja) Motor Induksi Tiga Fasa, Jurusan Teknik Elektro, Fakultas Teknik, Universitas Halu Oleo, Kendari, 2016, http://sitedi.uho.ac.id/uploads_sitedi/E1D111012_sitedi_tugas\%20akhir\%20pdf.pdf diakses 2 November 2017

4. http://siapbelajar.com/wp-content/uploads/2013/09/6_102Teknik-Listrik-Indus-Jilid-2.pdf

5. Muhammad Robith, Prinsip Kerja Motor Induksi 1 Fasa, 2015 http://www.insinyoer.com/prinsipkerja-motor-induksi-1-fasa/, diakses 3 November 2017

6. Sistem Proteksi Motor Induksi 3 Fasa Dari GangguanTidak Seimbang Dan Temperatur Lebih Menggunakan Mikrokontroller (SKRIPSI) Oleh Didit Very Kuswoyo http://digilib.unila.ac.id/23770/3/SKRIPSI\%20TANPA\%20BAB\%20PEMBAHASAN.pdf 